\title{
COIN BASED MOBILE CHARGER USING RFID WITH PV FOR PUBLIC USAGE
}

\author{
A.Manikandan ${ }^{1}$, U.Ganesan ${ }^{2}$, Vijayaragavan.M ${ }^{3}$ \\ ${ }^{1,2}$ UG Scholar, Mailam Engineering College, Mailam. \\ ${ }^{3}$ Assistant Professor, Department of EEE, Mailam Engineering College, \\ mrvijay.ragavan@gmail.com
}

\begin{abstract}
The idea of this coin based mobile charger using solar panel helps us in the emergency posture by the way of charging our mobile. In this generation and the future generation the mobile is playing and will be play the another role of our life. The daily usage of this mobile phone, it should be alive at every seconds without dead. In the way to give the life to this character our coin based mobile charger using solar panel is used in the public places where the movement of human being is essential with acceleration. we mostly face the low battery situation in the long time conversation, playing games, songs, at the interesting and serious condition the battery going to low means it brings our mood to irritation and tension. To deal with these disappointment coin based mobile charger is used by suddenly plugging the charger to the mobile and putting the 1Re coin to the validitor then the charging process taken off. These working of coin and RFID based mobile charger is simplified and used in where there is no gird power is obtained by the help of solar panel.
\end{abstract}

Keywords: RFID, Microcontroller.

\section{NESSECITY :}

This mobile charger is used by the people at the time of unavailability of the charger at the particular situation. It can also be used in the in sufficiency of grid power by solar system. In colleges, parking area, hotels, bus stands, railway station, play station, markets, road side, shops, hospitals.

\section{INTRODUCTION}

In this developing society we know that mobile phones are ruling the most part of our human life. The life of the mobile phone is decided by the battery from charing capacity. The battery is slow down by often usage of the applications in the mobile phone (like whatsapp, facebook, twitter social network, games, calls, skype, vedio calls, camera, musics, etc google).

We cannot control by without using the mobile phone, but can manage the battery life without dead condition. In homes we can charge our mobile phones easily with our charger which is essential. But in our daily rotation we cannot able to get the charger at all the time we go. We have the habit of taking the mobile phones regularly but not the charging at all situation. At that time the coin based mobile charger take the role. However when mobile charge is low in the middle conversation, important message pass, our mind becomes tensed at that situation by seeing the coin based mobile charger in the public places it makes feel free. Whereas in the rural area they are struggling without the grid power in that area our coin based mobile charger using solar panel stands strength in those areas. Solar panel system is spreading in all the country so we using the solar panel for the advance purpose.

\section{BLOCK DIAGRAM}

The block diagram has the three stages

* Input stage

* Middle stage

* Output stages

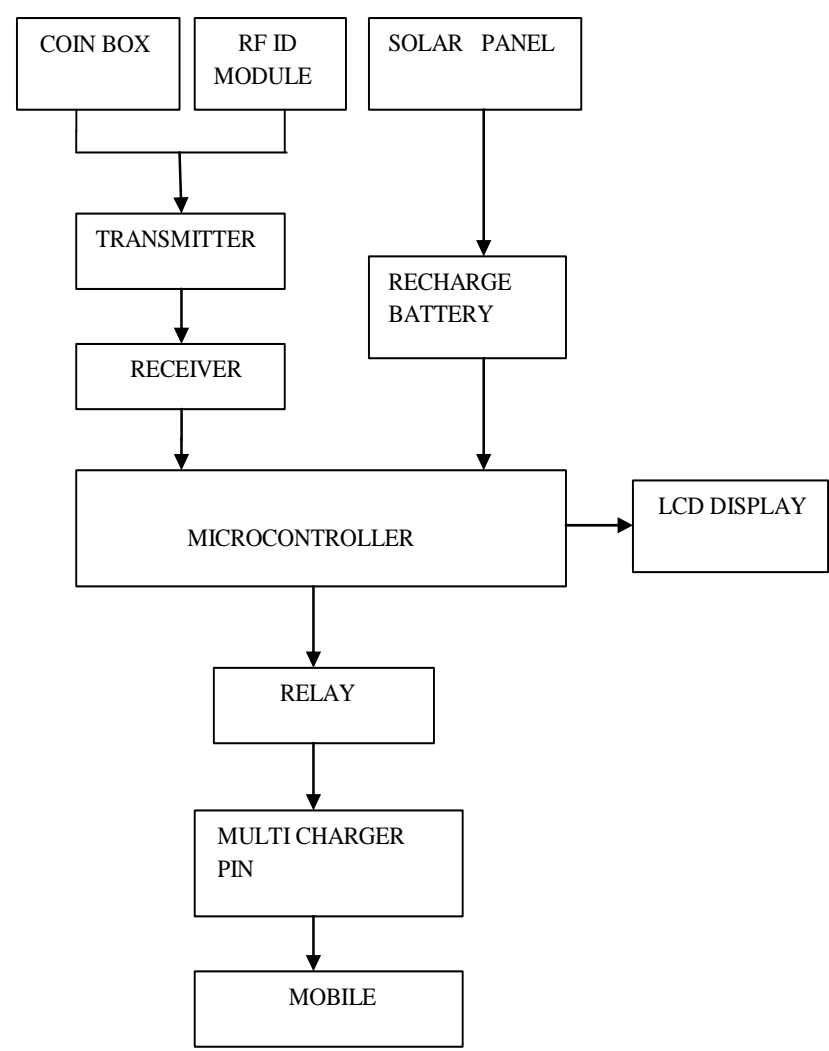

Fig 1. Block diagram of coin based mobile charger 


\subsection{INPUT STAGE}

In input stage, first step of this stage. The coin is to be inserted in a coin box and then the work of a transmitter and receiver is taken place. The RFID is also used for the people who not have a coin and can also requires for long time period of charging. RFID verification acquires it transmit and receives the signal both the coin and RFID signals are send to the micro controller. The solar panel is connected to the rechargeable battery. Where the grid power is not available, it stores the power and supply whenever it necessary battery charge draw the power to the supply.
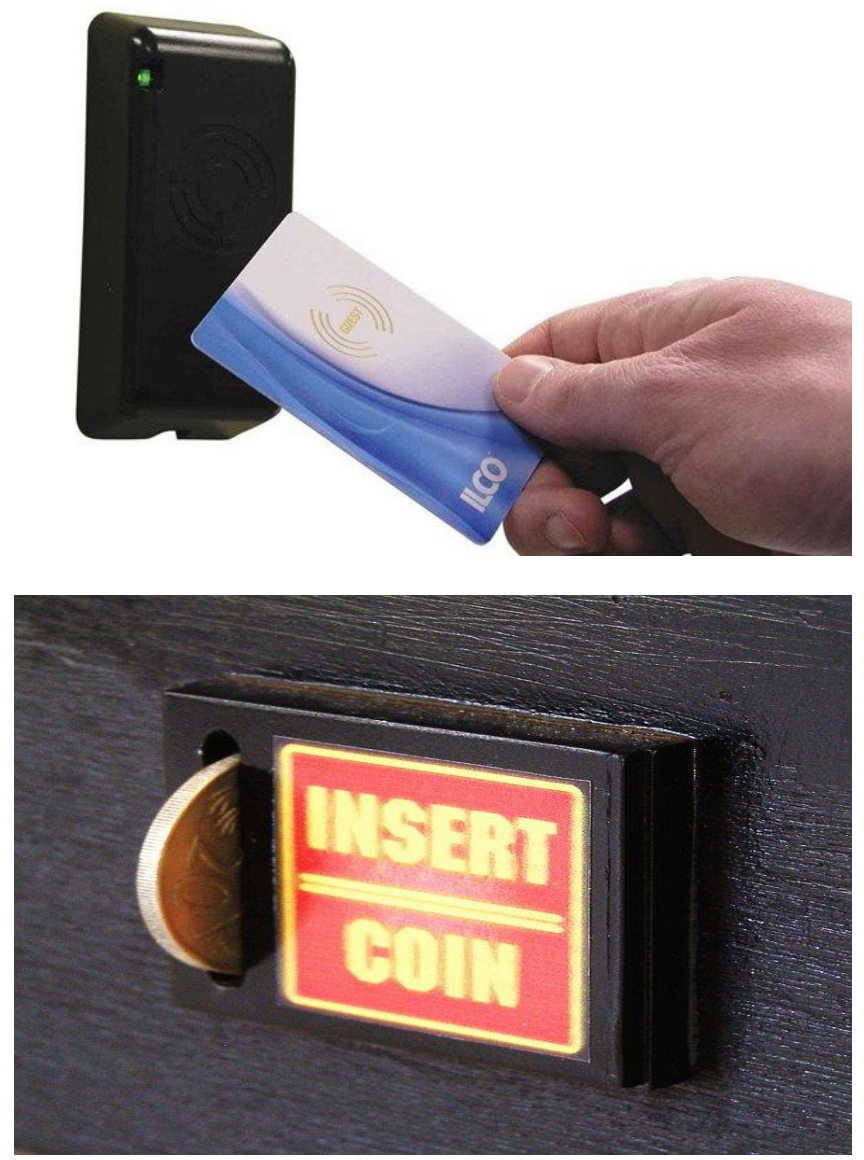

Fig 2. Coin and RFID card inserting setup

\subsection{Middle Stage}

Microcontroller is the middle stage. Microcontroller works only when the command receives from .RFID (or) coin box.LCD display shows all the process of controller and inserted of coin or RFID card swaps.

\subsection{Output Stage}

The output stage is called the charging process (or) completion of charge. The supply from the relay given to the mobile charger pin. By connecting the mobile phone to the mobile charger pin the number of coin insertion (or)RFID card swap according to these amount the completion of charge is taken placed.

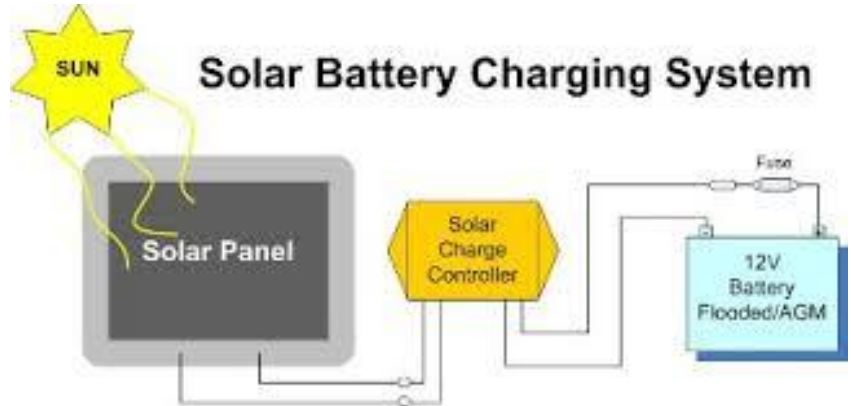

Fig 3. Solar Battery Charging System

\section{CHARGER}

Cellphone chargers are nothing but AC to DC converters. They take an input of 220 volt $\mathrm{AC}$ and give an output voltage around 5volt DC.Generally the output voltage of the charger is in the range of 5 to 5.5 volts DC.

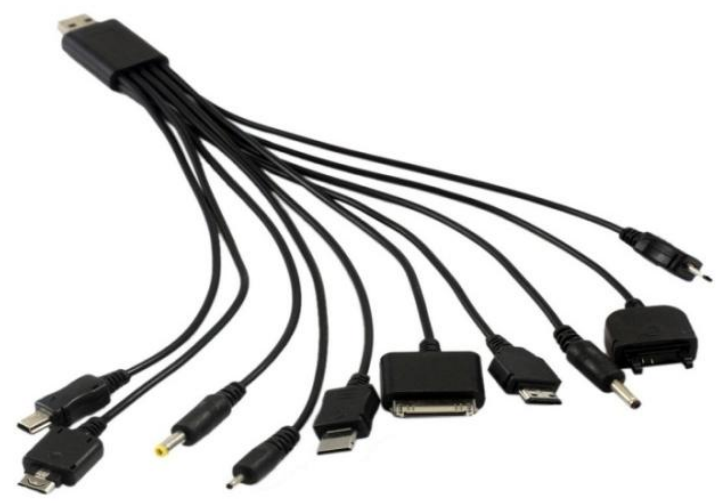

Fig 4. Multicharger Pins Used For Mobiles

\section{ALGORITHM}

1) Start

2) Insertion of coin

3) Collect the coin

4) Swap RFID card

5) Command to the microcontroller

6) Battery charging

7) Supply to the mobile charger pin

8) Mobile charging will start

9) Completion of charger will displayed on LCD

10) Stop

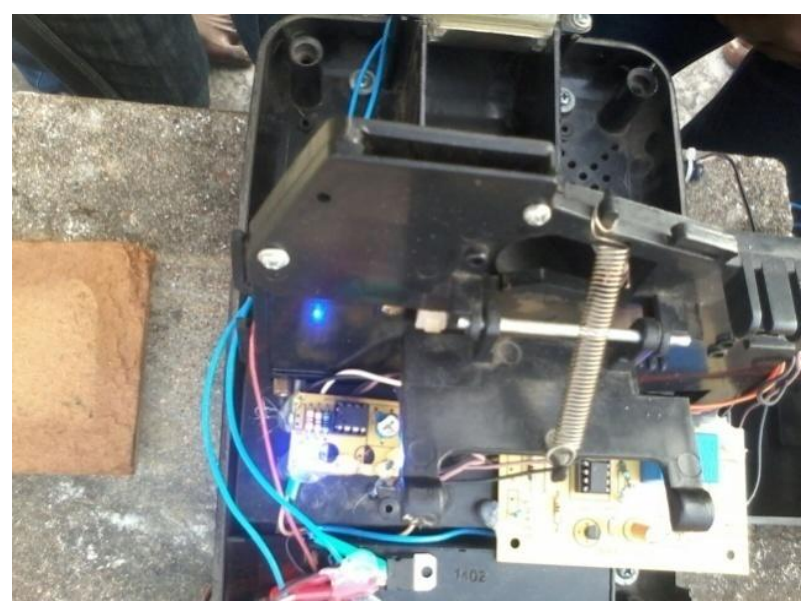




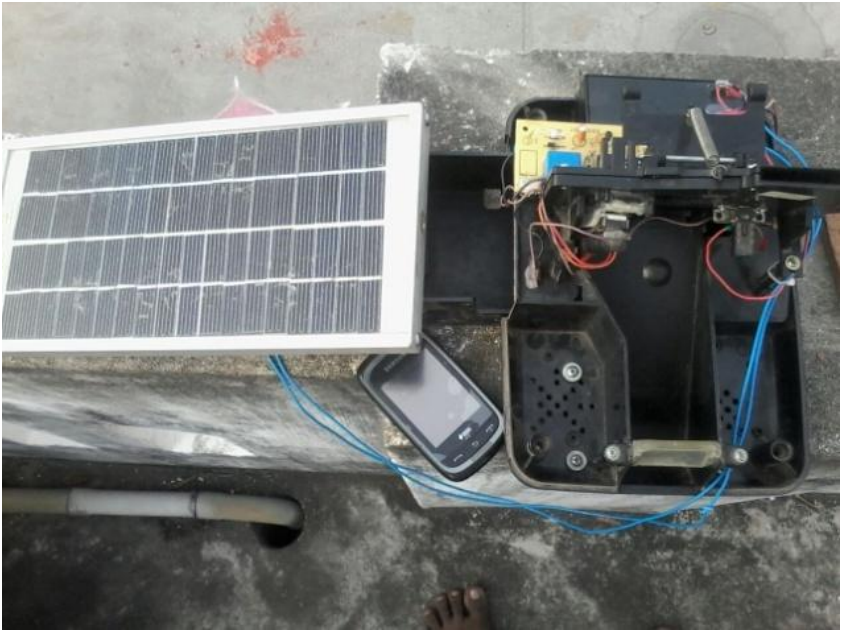

Fig 5. Experimental setup

\section{FLOW CHART}

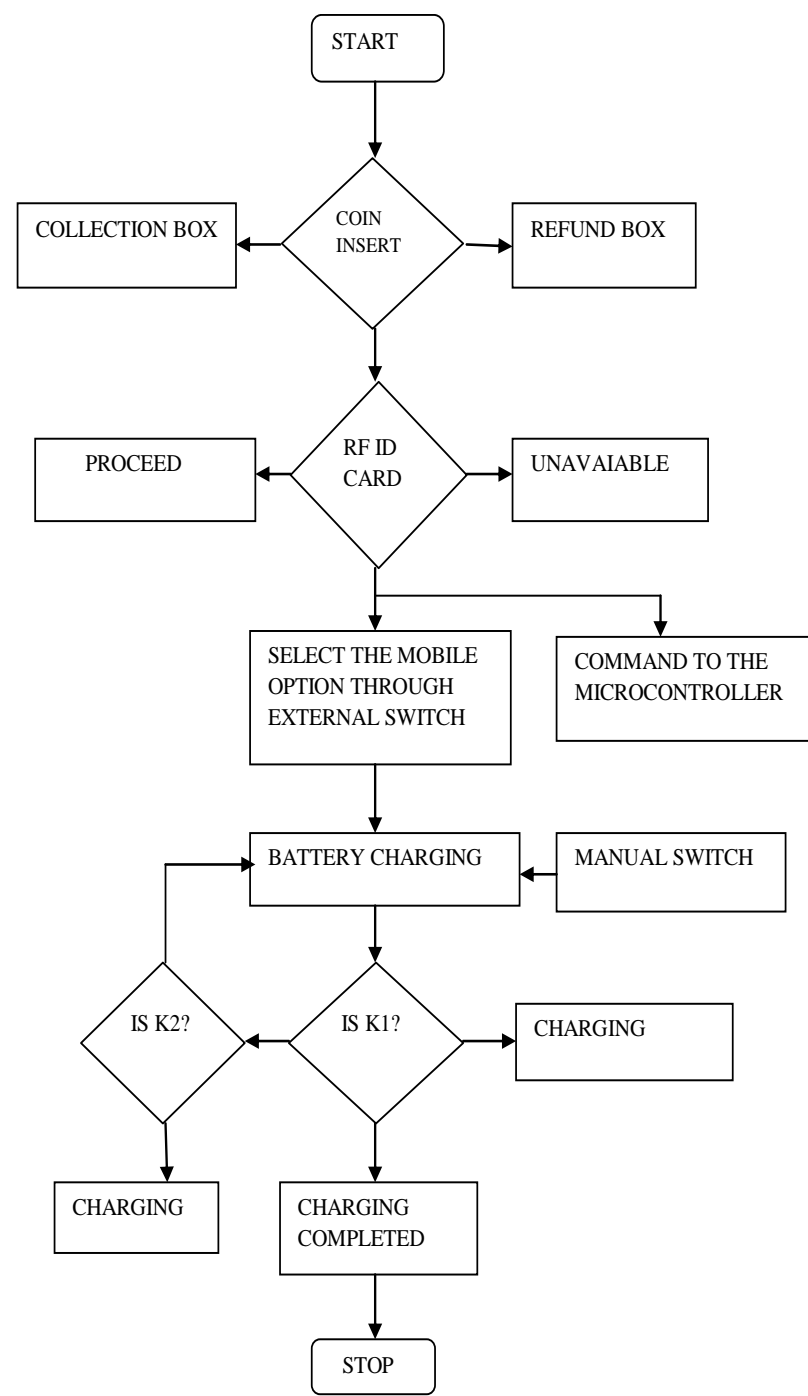

Fig 6. Flowchart of coin based mobile charger

\section{FUTURE CONSIDERATION}

This idea can be used for many purposes instead for charging the mobile. It used for buying foods in the hotels, snacks in the stores, toys in the stationery by inserting the require amount to that particular product. The tickets buying in the trains, buses in the fast moving society by this idea the reduction of queue in the public places.

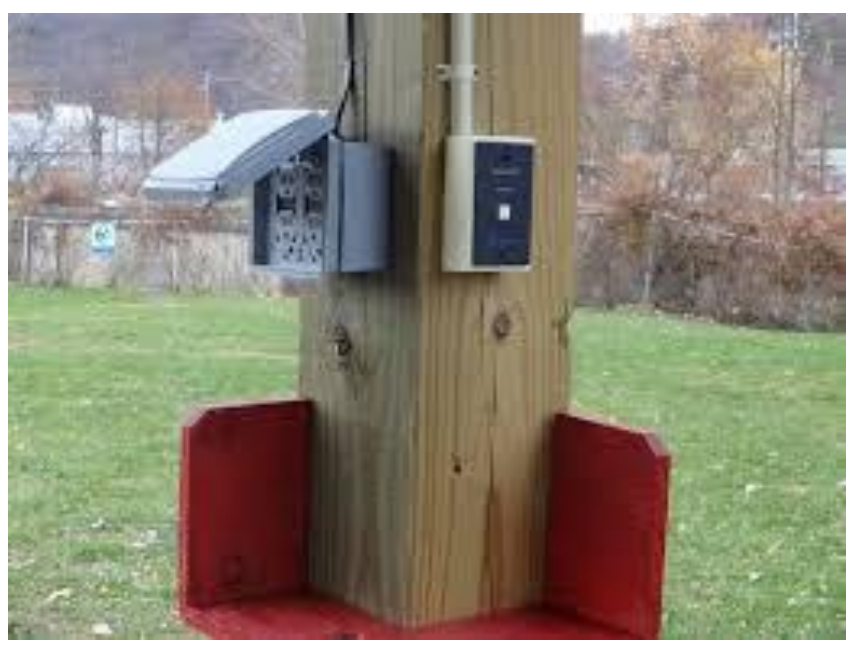

Fig 7. Smart Setup of Mobile Charging

\section{ADVANTAGE}

* Simple and hand efficient

* Less expensive

* Reduced man power

* Low power consumption

* More useful to save energy from sun and intelligent tracking solar energy

* Effectively receive maximum energy from sun towards earth rotation

\section{APPLICATION}

* Industrial applications

* Power management systems

* Solar systems

The coin based mobile phone charger is very useful to public for using coin to charge for the mobile phone in any places.

\section{CONCULSION}

To present this paper is to bring aware of the coin based mobile charger to the public places. The necessity of mobile phone communication is vast increased in this technology life. So usage time of mobiles is also increased without decreasing the battery charge the coin based mobile charge is used at the time of unavailability of charger with us.

Thus this paper is useful to the rural people were the insufficiency of grid power by solar panel and RFID is also used in the sense of not having the coin. 


\section{REFERENCES}

[1] S.B.Shridevi, A.Sai.Suneel, K.Nalini "Coin based mobile charger using Solar tracking system", IJAREC, pp 741-745,Sept. 2013.

[2] K. M. Trautz, P. P. Jenkins, R. J. Walters, D. Scheiman, R. Hoheisel, R. Tatavarti, R. Chan, H. Miyamoto, J. G. Adams, V. C. Elarde, and J. Grimsley "Mobile Solar Power",IEEE, pp 535-541,Jan. 2013.

[3] F. Boico, Brad L. K. Shujaee, "Solar Battery Chargers for NiMH Batteries" IEEE Trans. Power Electronics, vol. 22, no. 5, pp 1600-1609, Sept. 2007.

[4] J. Eakburanawat, I. Boonyaroonate, "Development of a thermoelectric battery-charger with microcontroller-based maximum power point tracking technique", Applied Energy 83,pp- 687-704 , ELSEVIER, 2006 